\title{
4. DATA COMMUNICATION AND DISTANCE LEARNING METHODOLOGIES FOR TECHNICIANS TRAINING
}

\author{
I. S. Zilberstein, \\ Director School of Technology, \\ the Open University of Israel \\ 16 Klausner Street, Tel-Aviv, Israel \\ Tel: 972-3-6423236, 972-3-6460191 \\ Fax: 972-3-6460068 \\ E-mail: israel_z@cet.ac.il \\ B. Z. Barta, \\ Centre for Educational Technology \\ 16 Klausner Street, Tel-Aviv, Israel \\ Tel: 972-4-850-9569 \\ E-mail: ben@barcode.co.il
}

\begin{abstract}
Within the continuous efforts of the School of Technology of the Open University in Israel to improve the teaching/learning process, new methodologies were adapted: use of engineering and simulation software and the use of data communications for distance learning (DCDL). The DCDL system uses for educational purposes most of the facilities available on the web. The educational, training and social aspects of the rationale for using DCDL are shortly mentioned. Examples of application in electronics studies and the data collected during the first, limited scale implementation of the system are described.
\end{abstract}

\section{Keywords}

Distance Learning, Vocational Education, Electronics, Methodologies, Courseware

The original version of this chapter was revised: The copyright line was incorrect. This has been corrected. The Erratum to this chapter is available at DOI: 10.1007/978-0-387-35393-7_22 


\section{Introduction}

The School of Technology of the Open University of Israel was established some 11 years ago, as a nation wide distance learning system for training Technicians and Practical Engineers. Technician is one year post secondary level and Practical Engineer two years.

The School developed about 20 courses in each of 3 Engineering fields:

Electronics, Software Engineering, and Industrial Management.

A technician must complete 13 courses for the diploma and a Practical Engineer 18 courses.

Each course used until recently all or most of the following learning methodologies: Self Study written units, Home laboratories, Software for home use, Group sessions at study centers, Weekly telephone assistance, Home assignments and practical work, Final exam in each course.

\section{New Methodologies}

Updating the study methods and means in recent years involved two main directions:

1. Intensive use of Engineering and Simulation software

2. Introducing Data Communication for Distance Learning (DCDL)

The first updating direction includes the use of applications, simulation and system analysis packages which were adapted for educational purposes from points of view of complexity, user friendliness, and course content.

Some examples are: Access for the courses: 'Data Bases' and 'Information Systems'. EWB and TESS for studying some courses in Electronics and Communication Systems. The simulation packages being used in Electronics and Industrial Management courses are sometimes very good substitutes for laboratory experimentation and fault finding conducted previously on real hardware training systems. In addition, the software packages have broader and deeper analysis and experimentation possibilities than the hardware training systems.

The computerized activities with these packages are conducted in some cases on the personal computers of students at home and in other cases on networked computer classes at study centers spread all over the country with tutors guidance and assistance.

The considerations involved in using these software packages either as networked computer classes at study centers or as stand alone are:

1. Availability of course material for self study and how much tutorial assistance will be needed for the work with the package, or else the difficulties or even unavailability of materials for home use and tutoring.

2. The amount of the pedagogic contribution of team work in a networked class. 
3. Availability of home computers and availability of computer classes in a particular student location.

4. Price of the package for single user versus site license in the classes.

\section{Data Communication For Distance Learning (DCDL)}

\subsection{Main features}

The DCDL system was introduced in the past few years in several Open University academic courses, and we at the School of Technology are preparing to use the system in a few courses, beginning in March 1998. Every student receives a Modem (if he doesn't have one), a communication software package, an e-mail address, and basic operation instructions, in order to connect to the system.

The main features of the DCDL system are:

1. E mail correspondence - students between themselves, students and tutor, students and tutor with their instruction manager at the School of Technology. Messages from the course tutor or instruction manager to the students are about: course operation, supplying additional material, learning procedures, exercising new Internet relevant sites, etc.

2. Discussion groups or asynchronous conferences, between the students and with the tutor. The tutor will pose a problem to all the students via e mail and the students will discuss options and solutions. 'External' guest experts will also pose issues for discussion. The possibility to connect students to various news groups available on the net will also be studied.

3. Opening an Internet site for the course and using it for guided access as well as personal access to Internet resources dealing with the technological topics of the course. A FAQ facility is also investigated. Questions raised by students in the past alongside misconceptions expressed by students will be presented in a FAQ file.

4. Interactive self study courseware that integrates Internet possibilities in the computer based learning. It will be described in more detail further on.

Features 1 and 2 of the above and in some sense 3 are technical possibilities supplied by the system for learners and teachers. Some aspects of feature 3 and mainly feature 4 are those containing reach pedagogical and instructional content. 


\subsection{The Rationale for $D C D L$}

Using DCDL for our training system has several goals, professional, pedagogical and social.

Any recently trained professional in Electronics, Informatics and many other areas, has to be able to use the Internet facilities in his daily work. To be able to browse for information and technical data, purchase, make bids and proposals, etc.

Another development, gradually introduced by Industry is that of team work based on data communications, having team members working from disperse locations.

Starting to use such facilities while being educated, will not only augment the educational process but will have the graduates better prepared for their future professional activities.

Pedagogically, the use of DCDL promises to be a valuable add-on to the other methodologies and materials already in use. It is the most efficient way to provide updates to existing written materials or educational software available at students' homes. It allows to work from the home computers, interactively with centrally located packages, to get tutor's interaction, on line while working with the package. Additional materials and support can be provided to individuals and groups according to their specific needs - at a level of interaction, presentation quality, and speed of distribution which cannot be obtained with any other conventional learning means.

From the social point of view, one of the problems of distance learning is the lack of daily and easy contact with the tutors and with other students. Efficient data communication using all the facilities provided by the Internet, is a good and costeffective substitute to face to face contact. It gives the feeling of belonging to a group and of having its support, even if students get to the system from different places and at different times.

Having these issues in mind, the presently developed courses, as described further on, will provide the opportunity to test these approaches and to evaluate their efficiency.

\section{Applying DCDL In Electronics Studies}

The DCDL method is introduced experimentally in 2 Electronics courses: 'Beginners Electronics Circuits' and 'Advanced Electronics Circuits'. We chose a main topic of Electronics Circuits in which students have difficulties and which is included in both courses at different levels: 'Operational Amplifiers and their applications'. In addition to opening the Web site for these courses and using the correspondence and e mail facilities, we are developing courseware which presents the material to be learnt in a staggered manner. In each stage only the minimal information needed for that stage is presented, and the student is asked for interactive response in order to proceed. The distant computerized learning system presents problems at various levels and the student can ask for clues, and/or receive partial solution and/or receive the complete solution. The basic exercises and problems posed are suitable for the beginners course while the problems including 
industrial applications and circuit analysis are suited to the level and complexity of the advanced course. The system also includes summaries and abstracts of the basic concepts and principles of the Electronics topic involved. The student can access them when he feels the need for it.

The integration of the Internet resources and learning possibilities in this system will be done in several ways:

1. General links in the courseware to sites teaching relevant Electronics topics, for enrichment and further study of the topic.

2. Specific links in the self study units of the courses - these will include specific explanations and/or instructions regarding proper pages of Internet sites, in which relevant material is presented.

3. Internet tasks - some assignments and problems in the courseware and in other distance learning means of the Electronics courses need Internet resources in order to reach proper solutions. Knowledge of how to access and retrieve information from one or more sites and data bases is needed.

4. Group project assignment - these are large assignments intended for collaborative work of 2-4 students who have to use the correspondence and discussion capabilities of the system as well as Internet resources and data bases in order to accomplish the project. The projects are taken from real life problems that need investigation and analysis before beginning solving them. This investigation should be done by team work using the DCDL system. The team has to work together to find a proper solution, analyze it, and prepare a proper report on it.

Some examples of the Internet tasks and assignments are following. Our comments in parentheses explain the underlying instructional considerations:

1. What is a Darlington circuit and what is it used for?

2. (This type of circuit has not been studied yet so this is an investigation task in which the Internet resources and the specific links given in the course site must be explored.)

3. Detail the differences between an ideal Diode (operational Amplifier) and a real one. Use up-to-date data of Semiconductor producers, such as Philips, Motorola, etc. (Here, the student has to deal with real life situations of finding data files of components and electronic devices, using the Net.)

An example of the learning software integrated

\section{Problem}

A waveform has a positive amplitude of $\left(\mathrm{V}_{1}\right)$ and a negative amplitude of $\left(-V_{2}\right)$. Use two peak detectors and design a circuit, in the output of which we will get a DC voltage of $\left(V_{1}+V_{2}\right)$.

Links are available to:

1. clue 
2. partial solution

3. full solution

4. basic concepts

5. instructor's help - on line or off line,

6. FAQ related to the problem.

An interesting and further reaching instructional idea which we consider to incorporate in future courses is to use a software simulation package which is available on the Net and actually 'build' the circuit that solves the problem, connect the input voltage and investigate the output voltage. The packages on the Net, we refer to are demos or student versions of large packages used in industry but they will suffice for the circuit complexity of the course.

In order to increase student's motivation and willingness to use the system, we chose to teach by DCDL such subjects that are included in the final state examinations for the Technician/Practical Engineer diploma.

We intend that the development teams will update the courseware according to the feedback from its operation as well as the changes in the curriculum and the state examinations.

\section{Usage Statistics}

First run-in implementation of DCDL for the electronics course, started in March 1998 with a limited number of students - the main goal being to debug the system and to get a rude first evaluation of the way students use it.

The course is taken by a group of 25 students which were offered to access the system on a volunteer basis. They have been allowed to use the system as they wish, with the option to accomplish some web-based assignments instead of the regular assignments included in the course.

Weekly data has been collected on the access of the various system facilities, the assessing sites and the frequency of students' accesses. Comments and suggestions of the students have been collected as well. Some of these get immediate response and full analysis is to be done at the end of the semester. About 10 students are accessing the site weekly.

Some 150 pages are requested weekly with no fixed patterns of usage on the different days of the week. It is clear that the peak of the request is not on weekends only but one of the week days randomly.

About $20 \%$ of the pages requested are from the news groups; $30-40 \%$ from exercises and assignments; about $5 \%$ are requests to other sites accessed through our system. The rest splits between general information about the site, timetables, etc.

From this preliminary data, we can conclude that the system is operating correctly and that some of the students find it useful and access it regularly. There is as yet no evaluation of its benefits to the learning process. 
It is not yet clearly known why some of the students did not use the system. It may be caused by the habit to use printed material or by the limited access some may have to the computer. This fact will be investigated in future runs of the course.

\section{Summary}

The DCDL as described so far, will be used for several semesters as an additional methodology to the self study written material which is still the main learning method and to the other conventional distance learning methodologies. We intend in the future to put more and more weight on the DCDL and the use of simulation software instead of the written material and the hardware laboratories. The more the availability of computers, software packages and Internet access of the students increase, the more pedagogic emphasis will be on DCDL and similar methodologies as well as the intensive use of 'Virtual laboratories' through simulation and analysis software.

By the beginning of August we will have some conclusions from the first run of the DCDL in the several School of Technology courses and these will be presented at the Working Group conference

\section{References}

Zilberstein, I. and Barta, B.Z. (1992) Using Software and Hardware in Distant Training System for Computer Professionals, in Proceedings of FIE Conference, 755-762, Vanderbilt University, U.S.A.

Zilberstein, I.S. (1993) Implementation of Computerized learning methods in secondary electronics education, in IFP Transactions A 35 (ed. B.Z. Barta, Eccelston, Hamblish), IFIP Working Group 3.4, Soest.

Zilberstein, I. (1997) Assessment Methods in Distance Learning Post Secondary Technology Education, Proceedings of PATT-8 Conference, (ed. Ilja Mottier and Marc J. de Vries), Shweningen, Netherlands.

\section{Biography}

\section{Israel S. Zilberstein}

Born 1946, received B.Sc. in Electrical Engineering 1967. Since 1970, Project Director and since 1976 Head of Technology Education Division of the Center for Educational technology (CET) in Israel as well as Head of Vocational Training through self study methods at the Open University of Israel. Since 1983 Head of Development of the School of Technology of the Open University. Since 1996 Director of the School of Technology. Participated and presented at IFIP WG3.4 Conferences in 1984, 1990 (with the WCCE), 1991, 1993 and also at FIE 1992 Conference in USA, UNESCO, 2000+ Conference 1993 in Paris, IRNTED 1994 Conference in Italy, IOSTE 1996 Conference in Canada, JISTEC 1996 in Jerusalem, PATT 81997 in the Netherlands. Participated in Committees for Technology Education development and Telecommunications training at ORT STEP/LEAP 1995, 1996 and 1997 in South Africa. 


\section{Ben Z. Barta}

Born 1931, Ph.D. from Technion Israel. Consultant on Internet Working and Computers in Education. Retired. Chief Inspector for Computers in Education in the Ministry of Education, Israel, in charge of the coordination of R\&D projects and the implementation of computer education activities in the Israeli school system. Chair of IFIP's Working Group on Information Technology in Educational Management. Chaired IFIP's Working Group on Training and Education of IT Professionals. Chaired several Working Conferences, published and edited in the areas of teaching of Informatics and of computers in education. 